\title{
DRAFT-7/15/2015
}

Comments are welcome at bkeele@indiana.edu. This draft will be substantially revised. Please contact me before citing to ensure you can cite the latest draft.

\section{Copyright and Embargoes on Digital Collections}

\author{
Benjamin J. Keele
}

\section{Introduction}

While academic libraries generally provide researchers wide access to their collections, sometimes libraries limit access. Archives restrict access to collections of papers when required by donor agreements. Privacy concerns lead to limiting access and redacting records. Rare book librarians carefully control access to especially scarce or fragile materials. Copyright, especially for digital collections, is another factor that leads to constraints on collections and access. Works can remain under copyright for a very long time; many works created today will likely be protected for over one hundred years, so these access restrictions may seem contrary to libraries' collective mission to provide access to information and intellectual works. One of the main advantages to digitizing and assembling such collections is that access will expand beyond the library's walls and traditional constituencies.

If a major purpose of libraries is to collect, preserve, and present information, then when are access restrictions consistent with libraries' motivating principles? What is the point of collecting materials when 
researchers cannot use them? Do access restrictions motivated by copyright exemplify how copyright fails to promote knowledge and the "useful arts and sciences"? If these restrictions constitute an appropriate way for libraries to reduce copyright concerns, how can the restrictions be implemented to best further the library's mission?

Libraries can justifiably impose access restrictions to address copyright concerns, generally when the restrictions will enable access for researchers in the future. Deciding when to limit access, and what form those limits will take, requires considering copyright law's effect on library digital collections, technical and policy options, and characteristics of works in the collections.

\section{Copyright and Library Collections}

Copyright has long influenced the publishing industry that supplies libraries, and regulated many uses of physical items in library collections. Copyright's reach is much stronger and more pervasive regarding assembling and using digital collections. This is due to a few crucial differences between how libraries acquire physical and digital works, and the actions researchers usually take to make meaningful use of a library's resources.

Copyright provides authors exclusive rights: making copies of works, distributing works, making derivative works, performing works, and displaying works. To gain copyright, works must be fixed and original. A work can be almost any intellectual creation, including books, articles, images, and musical compositions. An unrecorded conversation or thoughts in 
one's mind are not fixed and not copyrightable. Collections of facts that require no originality, such as a phone directory, are not copyrightable, either. Any works in a library are fixed, but sets of data are sometimes added to library collections. Since the data sets are composed of facts, they might not be copyrightable. However, the European Union has a separate database right that may apply. Some advocates call for researchers, especially scientists, to release their data sets under very permissive licenses, or even waive all intellectual property rights and place the data sets in the public domain.

A crucial copyright rule is the first sale doctrine. It provides that when an author sells a copy of a work, the exclusive rights relating to that copy are largely eliminated. This is why when one finishes reading a book she purchased, she can sell, donate, or lend. First sale is why a library can lend copies that it purchases, and copies given to it.

Libraries have long obtained books (and magazines, documents, records, and the like) through purchase or gift. Libraries generally own their physical collections, and that ownership, with first sale, give libraries the ability to lend and provide access to their collections with virtually no copyright worries. Researchers reading a book or taking notes are not copying, performing, displaying, or making derivative works. Lending a book is distribution, but first sale means the copyright holder doesn't control distribution of that copy anymore. 
When researchers and libraries make copies, Section 108 of the Copyright Act provides a good deal of protection. Section 108 is sometimes called the library exception because it provides special protections for libraries with publicly accessible collections. Under Section 108, libraries provide copies for personal research use without fear of copyright infringement. As long as the researcher takes ownership of the copy and uses it for personal and research purposes, the library does not infringe a copyright. There are other formalities with which libraries must comply, such as placing a copyright notice on each copy it makes for a researcher. Another example of copies made under Section 108 is filling requests from other libraries. This inter-library sharing extends the benefits for a library's collections to many other researchers.

For digital works, the circumstances are almost reversed. When libraries acquire digital works, they are usually licensed from the publisher and hosted on the publisher's computers. While license terms can vary widely, provisions limiting access to specific classes of researchers and limiting the number of copies that can be distributed are common. Libraries essentially rent the materials rather than owning them, and if a library cancels a subscription, access to those materials ends. Section 108 only applies to works the library owns, and many licenses do not permit interlibrary loan or distribution of copies outside the class of authorized users. Section 108 protects some copying for preservation purposes, but the 
provision was clearly written with physical items in mind. Copying is limited to three copies, and access must only be provided within the physical facilities of the library. Section 108 is not suitable protection for libraries creating and distributing copies of digital works.

Scholars have called for reforms to Section 108 that reflect the realities of digital collections, but the Section 108 Study Group, a committee of librarians, publishers, and other stakeholders assembled by the Copyright Office, was unable to reach agreement, and there appears to be little political will propelling updates in the near future. [Further discussion on Section 108 and proposals for reform needed] Perhaps the "Next Great Copyright Act" will include updates, but given the corporate media industry's great influence on international copyright treaties, legislation, and regulations, this is not something libraries should count on.

Some publishers offer "ownership" or "perpetual access" options by which libraries obtain their own digital copies or the right to continued access to purchased content. Perpetual access relies on the publisher's ability and willingness to maintain the content online long term, and libraries owning the digital files are then usually responsible for providing effective access to researchers.

Typical use of digital collections implicates more rights protected by copyright. While a researcher can borrow and read a book without making any copies, most uses of a digital equivalent will involve making a copy on the 
researcher's device, touching on the reproduction and distribution rights. Enabling researchers to view a digital work from a library's servers can infringe the public display right or, for audio or video works, public performance right. When a researcher pulls a book from a library shelf, borrows, and reads it, she and the library are not doing anything that could be infringe a copyright holder's right. However, a researcher finding, viewing, and downloading a digital work is taking actions entangled by copyright rights and most likely a contract between the library and publisher. This means libraries must consider options beyond purchase and gift when adding copies to their digital collections.

There are a number of ways in which libraries can assemble digital collections, but this paper will largely focus on two common scenarios: a library digitizing its entire collection of doctoral dissertations, and a library collecting digital copies of all scholarly works by its faculty. The institutional repositories are hosted on servers owned or controlled by the library.

These cases most clearly expose the library to copyright infringement risk. A library could regard its licensed content or lists of links to openly accessible content as part of its collection, but in those instances the library itself is not creating or distributing copies or distributing. At worst the library could be liable for contributory or vicarious copyright infringement, but those risks are minor compared to the risks assumed by a library creating copies. 
For the dissertation digitization example, the library has a large collection of works, each of which have different copyright holders and statuses. The collection has works from a variety of disciplines and a wide range of creation dates. The library either performs or directs the creation of copies, and provides access to the copies. These actions could infringe copyright holders' reproduction, display, and distribution rights. For the faculty scholarship example, the library gathers works that have been published in a variety of venues. The question of who holds copyright in each work depends on the agreement between the publisher and author. Copyright automatically vests with the author, and any transfer of copyright or exclusive licenses requires a written agreement.

Both of these examples have traits in common that implicate copyright. The dissertation and faculty scholarship examples each require collecting works that have highly variable and, most often, uncertain copyright statuses. Under United States copyright law, whether a work is still copyrighted depends on publication date, where the work was first published, and whether the work's copyright was registered or renewed. Some of the copyrights will have been assigned to publishers, while others will have remained with the authors. Over time, some publishers will have been sold or simply dissolved, and when authors die, copyright passes to their descendants. All of this means libraries seeking permission to make and 
distribute copies of these works have to commit significant resources to determine a work's copyright status and locate the appropriate rights holder.

Another commonality between the dissertation and faculty works cases is that libraries generally establish these collections to provide open access to works. Open access is a movement to provide access to scholarly materials over the Internet without any cost beyond a computers and an Internet connection. Like many movements, there are several flavors, as well as some internal debate on what types of obstacles are consistent with calling a work open access. Gratis open access means a work can be freely read and copied for reading, but no more liberal permissions are necessary. Libre open access, on the other hand, expects that works will be freely accessible and have significant reuse permissions granted as well. Libre open access, then, is more demanding than gratis open access. For our examples, we will assume the libraries are focusing on gratis open access for their digital collections. Embargoes, since they prevent reading the complete content of a work, seem somewhat inconsistent with gratis or libre open access.

To help us understand when embargoes are appropriate for digital collections, we should examine other options libraries have for assembling and maintaining digital collections in accordance with copyright law.

\section{Permissive licenses}

One option for libraries is to only acquire works for which the library owns copyright or has a very permissive license that would sanction virtually 
all uses the library and its researchers would be likely to want. Creative Commons licenses and other, less common open licenses authorize many uses of works. The Creative Commons license suite offers several combinations of conditions to be placed on use of a work. All licenses require proper attribution of the work being used. The non-commercial condition prohibits commercial uses, though there is some controversy about the precise distinction line between commercial and non-commercial. The no derivatives condition forbids the creation of derivative works such as translations, and the share-alike condition requires that any new works resulting from the use be licensed under the same or a more permissive license. For most academic researchers, the share-alike or no derivative works variants are most likely to prevent any undesired uses. Libraries can also require copyright holders to assign copyright or grant permissions to the library that will enable any desired future uses.

These two options hold libraries to collecting only the low-hanging fruit of desired works. Authors and publishers that support open access and reuse of works produce Creative Commons-licensed works. Many authors cannot or do not retain rights in their works, instead assigning them to their publishers. Works produced before the open access movement and development of Creative Commons licenses are still under copyright, and many have or will become orphan works (works without certain or reachable copyright holders to contact for permission). 
If libraries are to assemble digital collections that they own, can preserve for future researchers, and can provide access to for present researchers, they will need to collect beyond openly licensed works. Other very valuable opportunities are obstructed by the high transactions costs inherent in locating copyright holders and obtaining permission. If libraries only collect and preserve works that are public domain or for which they have permission (through a grant from the copyright holder or an open license), then they risk losing two important benefits. First, works that are not digitized may be damaged or lost while libraries wait for the copyright to expire. Given how long copyrights last, this is a serious risk. Libraries that do not digitize works they cannot provide open access to in the present may not be able to provide open access in the future. Second, once in digital form, there are a number of beneficial, nonconsumptive uses that may be made of the works that do not infringe on the copyright holder's exclusive rights. Discovery and access restrictions and embargoes are tools that can reduce copyright concerns associated with these projects.

\section{Discovery and access restrictions}

The exclusive rights provided by copyright can be divided, and each use of each right can be viewed separately. This means that a library could make some uses of copyrighted works without infringing. Access and discovery restrictions are ways to make noninfringing uses and reduce the risk of infringing uses. Libraries can limit access to a work, prevent a 
researcher from discovering the work-that is, knowing that a work exist in a collection—or both. It is useful to distinguish between these different types of restrictions because they can serve different purposes when responding to copyright concerns.

First, let's consider access restrictions. The most common such restriction is the embargo. The library adds a digital work to its collection, but does not allow the accessing or downloading of the document. Often time limits are placed on embargoes, say, two years after publication beyond which the work will become publicly accessible.

Embargoes address copyright concerns in several ways. Many publishers now have policies and publication contracts that permit an author (and libraries the author deposits her works with) to post their works after an embargo period. These embargo periods have varied widely over time and across publishers. Some are as short as six months, while others have lasted as long as five years. Publishers impose the embargoes to protect subscription revenue and their brand as the primary publisher of the works. If libraries collect digital works and observe the applicable embargoes, they add them to their collections with publisher and author consent, reducing copyright risk.

Some authors request embargoes on their works, even without a publisher demand. Often this request is motivated by an intention to seek publication in a venue that will demand the privilege of being the first publication. For example, an author of a dissertation may embargo her work 
while seeking publication as a book or a series of articles. Other works may contain sensitive information that needs to pass regulatory hurdles. Embargoes due to publisher policy or author request almost always have expiration dates, an important feature; ideally, the embargo should be set so that access becomes available automatically at some point.

For some digital collections, indefinite embargos may be necessary. A good example of this is mass digitization projects. The digitization of a university's entire collection of theses and dissertations is an efficient way to preserve and provide much wider access to the research products of its students. Obtaining permissions for authors, with different preferences for distribution of their work, presents a major challenge.

Likewise, large collections of works, such as journal series or collections of papers by many different authors, may require the approach of digitizing and preserving the entire collection, but placing an embargo on each work until appropriate permissions are obtained. The embargo prevents copyright infringement due to the distribution or display of a work. Whether making copies for the collection through digitization constitutes infringement is a separate issue that would probably be handled through a fair use analysis. If permission for digitization had been obtained, then the embargo would not be necessary, unless it was agreed upon as a condition for permission. 
Aside from embargoing public access completely, libraries have a couple other options for limiting access to digital collections. Access could be limited to researchers within a defined group. Either requiring the researcher's computer to be within the library's facility, or requiring researchers to be logged into an account in the system holding the digital collection could enforce this.

Finally, a work could be embargoed, but with an added request button that alerts the library or author when a researcher wants access. This would prevent any automated access or indexing of the work and give the library or author the ability to decide each access request on a case-by-case basis. This may seem attractive initially because it preserves a measure of control over the work, but exercising that control by replying to requests has a cost of its own. Authors should be aware that it is their responsibility to grant or deny requests; if the library is responsible, there should be well-developed criteria for each collection or work so that access requests can be answered promptly and consistently.

Libraries can control whether a researcher can read or use a work in their digital collections; they can also control whether a researcher can even discover that the library is holding a work. This can be as simple as suppressing the item or collection record in the digital collection management system, which would prevent any researchers from knowing of a copy's existence in a collection. A no-index tag would tell indexing bots from search 
engines and harvesters to ignore the work. This option would let researchers in the collection system find an item, but prevent external search tools from finding it.

Perma, a service hosted at Harvard Law Library and operated by a consortium of academic law libraries, is a good example of discovery restrictions. Perma captures snapshots of online sources cited in legal scholarship. These snapshots are assigned unique URLs. Researchers with the URL, most likely found in the footnote citing the online source, will be taken directly to the snapshot. However, the snapshots are set with metadata tags that direct search engine crawlers to not index the snapshots. The main Perma site does not allow researchers to search all snapshots, and registered users can only search the snapshots they created. This no-indexing practice means that any use of the snapshots is closely tied to Perma's purpose of backing up sources cited in scholarly literature, and results of searches for popular sites will be uncluttered by snapshots.

When a Perma user creates a snapshot of a web page that has a noindex or no-archive tag in its metadata, Perma still captures the page, but it places it in a dark archive. This means that if a researcher follows the capture's URL, she will be presented with a notice that a capture exists, but only a library registered with Perma can access it. The researcher can obtain access from a library that participates in assembling Perma's digital collection. 
Other web archiving services have adopted similar systems of reducing copyright risk. The Internet Archive and Webcitation both allow users to create captures of web pages, and the Internet Archive has a crawler that regularly archives a wide range of sites. Thus far, web archives have not been subject to much litigation. This is partly due to the Digital Millennium Copyright Act's notice and takedown system. When a service provider posts content at the direction of users, as Perma and the others do, if a copyright holder notifies the provider of copyright infringement, the provider is shielded from liability for infringement if it takes down the content. The user that created the content can counter-notify and back her claim with a defense of her posting, at which point the user and copyright holder can resolve their dispute. For works that the library adds to its digital collections without user direction, the DMCA protections will not be helpful. The discovery and access limitations will still help a fair use argument, which the Internet Archive and Google have used in litigation regarding their use of crawlers that copy and index web sites.

\section{Fair use analysis}

Libraries have special exceptions in the Copyright Act, and those are essential for shaping how libraries assemble and researchers use library collections. But there are exciting opportunities with digital collections that were not contemplated when the Copyright Act and later amendment were enacted. For these socially beneficial uses, the fair use doctrine fills the gaps. 
Fair use requires looking at four factors. While they are not the only things courts can consider when deciding if a given use is protected by fair use, they are given special emphasis. The factors are the purpose of the use, the nature of the work, the extent of the use, and the effect on the market for the work. The market effect factor used to be given greater emphasis by judges, but since Campbell v. Acuff-Rose, the purpose of the use has received more consideration, and if at use is regarded as transformational—putting the work to a use that the copyright holder did not or could not design the work for-the use is more likely to be protected. Let's consider how access and discovery protections can strengthen a fair use argument.

Imagine a library has digitized a collection of monographs that are not commercially available and relate to a topic that the library regards as one of its research strengths. It did not seek permission from the authors and publishers prior to digitizing the works and adding them to its institutional repository, but it has embargoed access to the works and forbidden web crawlers from indexing the works, though researchers can find the record pages using the repository's search tools.

First is the purpose factor. Educational and scholarly purposes are favored over commercial ones. An embargo on access certainly would not be construed as leaning toward a commercial use or one that would undermine the copyright holder's use or exploitation of the works. Rather, an embargo supports scholarly use of future researchers because it enables efficient 
digitization and preservation of the works for future researchers and uses that have not yet been anticipated.

Digitization for preservation purpose is generally regarded as supporting fair use. In HathiTrust v. Authors Guild, a panel of the Second Circuit held that HathiTrust's preservation of scanned works from its member libraries' print collections was fair use. HathiTrust embargoes access to works that are not public domain or open access, except that researchers accessing HathiTrust from a member library that has a print copy of the work in its print collection can access the digital copy. The Association of Research Libraries has promulgated a set of best practices for helping ensure that digitization projects will be found protected under the fair use doctrine. The ARL best practices code notes that preserving at-risk items, assembling special collections, collecting ephemeral web resources, and creating sets of works for non-consumptive uses (such as automated text analysis) are all uses that academic libraries generally regard as covered by fair use. Embargoes and discovery limits, since they prevent uses that might displace normal exploitation by copyright holders, support transformative and favored uses of digital works.

To support a fair use case, libraries imposing embargoes on works in their digital collections should take actions that further their purposes of preservation and eventual access. Libraries should develop a digital preservation plan to best ensure that digital works will be kept and migrated 
to formats that facilitate access by current technology. They should also actively seek to maximize eventual access. This includes encouraging minimal embargo periods, permitting access when possible, and seeking to determine works' copyright statuses, locating copyright holders, and obtaining permissions. HathiTrust has a robust program for determining which works are under copyright, and it allows copyright holders to grant permission for greater access. If a library created a digital collection, but then embargoed it and did not make good faith efforts toward eventual access, not only would that be an unfortunate use of resources, it would also undermine a court's confidence in the library's transformative purpose for creating the collection.

Embargoes do not affect the nature of the work factor. Limits on access do not change what the work is, making digitization of works of fiction and other works whose nature disfavors fair use more challenging, but not impossible. A weak case for one factor can be outweighed by strong cases for the other factors, and embargoes certainly do not make things any worse. Most mass digitization projects in academic libraries have focused on nonfiction works thus far, but fiction and artistic works are worthy of preservation as well, and may be the focus of future digitization initiatives. The amount and extent of the use generally examines the amount of the work that is used. The less of the work used, the more likely the use will be covered by fair use. If the use takes the heart of the work, the portion that 
is most important to the author and audience, fair use will probably not be found, even if that portion is small. The ARL Code of Best Practices suggests that a fair use case is strongest when the amount and extent of use is no more than is necessary for the purpose of the use. This is where embargos and discovery limitations make a difference.

When the purpose of digitization and storage in an institutional repository is to preserve the works for future researchers and eventually provide wide access, then using the entire work is appropriate. Future access and nonconsumptive uses would not be possible without adding the entire works to the collection. When assembling digital collections, comprehensiveness is important, and therefore creating complete copies is necessary for that purpose. Google and HathiTrust use a type of access restriction by only displaying snippets of works. Several federal courts of appeals have found snippet views to be covered by the fair use doctrine, indicating that access restrictions can support fair use.

Embargos make the greatest difference for the effect on the market factor. If the library's copy of a work is less accessible as a copy in the market, then the library's use is not detrimental to the copyright holder's exploitation of the work. A major concern for courts in fair use cases is whether the library's copies can substitute for the copies authorized by the copyright holder. Copies that are embargoed are less likely to substitute for copies that can be purchased or leased on the market. As we have reviewed, 
there are different types of discovery and access restrictions, and each type will have a different effect on the market for the work. A complete embargo, for however long it lasts, will have no effect on the market for the work, although perhaps if the expiration date for the embargo is known, there might be some effect if potential purchasers may decide to hold out for the work becoming open access. This effect is unlikely to be very great unless the library put a lot of resources into promoting the impending availability of a work.

Access restrictions that limit access to a particular class of researchers, say, patrons of a specific institution or members of an organization, or, going in the opposite direction, researchers without the access privileges afforded by an institutional affiliation, will only affect the market to the extent that the class of researchers is the core purchasing audience. The court would have to consider which potential buyers of the work comprise the market to which the copyright holder should expect to sell.

Discovery restrictions such as no-index tags can have a different effect on the market. Access may be available, but if the work tends to be effectively unknown to a relatively small group of researchers, then the market effect will be quite small. If the library's copy of a work can only be located through a specific URL or through the library's own discovery tools, then the market for the work will only be diminished to whatever degree those discovery methods are well known and used. Also, the library will know some basic 
information on the researchers using those tools, and it can connect that to the research or transformative purpose it is pursuing with the digital collection.

In summary, embargoes, whether in the form of discovery or access restrictions, can greatly strengthen a library's argument that the fair use doctrine protects its creation and distribution of copies of copyrighted works. The embargoes reduce the market effect of the library's copies and focus any uses of the copies on the research, educational, and transformative purposes favored by fair use. The library should take additional actions that are consistent with its purposes, which likely include preservation and eventual access for future researchers. That means the library should have reasonable digital preservation practices and seek to provide maximal access consistent with copyright by minimizing embargo duration, clarifying the copyright status of works, and requesting permissions from copyright holders when they are located.

\section{Conclusion}

Libraries are institutions dedicated to giving access to knowledge. They are also dedicated to preserving knowledge for future use. When used correctly, embargoes that limit access or discovery of works can help balance the needs of present and future researchers. Copyright risk presents an obstacle to mass digitization and assembling digital collections of works published elsewhere. It would be better that these collections are created 
sooner with embargoes than that they be impoverished or not made at all due to copyright risk. Embargoes support fair use protection of libraries' digital collections, and they can increase likelihood of obtaining copyright holder consent. With embargoes on collections, libraries make a commitment to future users that they will protect the intellectual works and make them available as soon as copyright law permits. 